\title{
UNA APROXIMACIÓN AL CONCEPTO SUJETO ${ }^{1}$ An Approach to the Subject Concept
}

\author{
Guillermo Bustamante Zamudio ${ }^{2}$ \\ Universidad Pedagógica Nacional
}

DOI: 10.17533/udea.rp.v10n1a01

Recibido: 2017-10-23 Aceptado: 2017-12-12

\begin{abstract}
Para citar este artículo en APA: Bustamante, Z. (2018). Una aproximación al concepto sujeto. Revista de Psicología Universidad de Antioquia, 10 (1), 17-44. DOI: 10.17533/udea. rp.v10n1a01
\end{abstract}

Resumen: Postulo un sujeto (Descartes-Lacan) en la medida en que: condesciende al lenguaje; asume la falta-de-ser concomitante (contra la tentación de disolverse en el Otro, de espetar su indigencia); cede algo de su pulsión; se las arregla con su síntoma; asume una postura y responde por las implicaciones de sus actos. Trabajando con el síntoma de cada uno — no con el saber-, la clínica psicoanalítica hace emerger este sujeto. Ello necesita un acto sin garantía, que desconecta del Otro, de lo aprendido, y otorga un lugar.

Por su parte, según Simondon, el sujeto persigue la individuación vital, tiene una problemática propia, y se representa como elemento y como dimensión del mundo. Sin embargo, esta serie es la subjetividad misma: el psiquismo es la lengua en nuestra cabeza; la problemática aparece por ser hablantes; es propia porque el lenguaje es autorreferencial; la representación elucubra sobre la lengua formalizada; y el sujeto se representa como dimensión del mundo porque se sabe vivo, gracias al lenguaje. Así, lo transindividual no resuelve colectivamente la problemática subjetiva, pues ésta es lingüística, no atañe a un ámbito nuevo de producción del sujeto. Una realidad preindividual no nos asocia al grupo; al contrario: una cadena de decisiones singulares crea el grupo.

Palabras-clave: lenguaje, falta-de-ser, otro, pulsión, postura.

Abstract. I postulate a subject (Descartes-Lacan) insofar as: condescending to language; assumes the lack-of-being concomitant (against the temptation of dissolving itself into the Other, of piercing its indigence); reduces some of its drive; manages with its symptom; takes a stand and answers at the implications of its acts. Working with each subject's symptom - not with the knowledge-, the psychoanalytic clinic makes this subject emerge. In this respect, it's needed an act without guarantee, which disconnects from the Other, from the learned, and grants a place in exchange.

In contrast, according to Simondon, the subject follows the vital individuation, it has its own problematic, and represents itself as an element and dimension of the world. However, this process is the subjectivity itself: the psychism is the language in our head; the problematic appears as we are speakers; it is own because of the language's self-referential condition; the representation lucubrates from

2 Artículo derivado de "Formación e investigación: una discusión a propósito de los seminarios de metodología de la investigación en la universidad. (DPG-438-16), financiado por la Universidad Pedagógica Nacional.

3 Profesor Titular Universidad Pedagógica Nacional. Correo electrónico: gbustamante@pedagogica. edu.co-guibuza@gmail.com; https://orcid.org/0000-0001-9341-3514 
the formalized language, and the subject represents itself as a dimension of the world because it acknowledges itself as alive, thanks to the language. Therefore, the transindividual does not resolve the subject's problematic collectively, since it is linguistic, it does not concern to a new area of the subjetc's production.
A preindividual reality does not associate us with the group; instead, a chain of singular decisions creates the group.

Keywords: language, lack-of-being, Other, drive, stand.

\section{Introducción}

En su idea de sujeto, Jacques Lacan volvió, una y otra vez, a las Meditaciones metafísicas de René Descartes. El texto le viene bien, pues 1) no psicologiza al sujeto, no lo llena de historia o de sentido (en esa dirección, aquí sólo relacionaré parte de la conceptualización psicoanalítica del sujeto con los apartados previos a las Meditaciones y con la primera meditación); y 2) no permite individuar al sujeto, pues le asigna una falta-de-ser (en esta dirección, relacionaré el concepto sujeto con algunos aspectos de la individuación, según Gilbert Simondon).

\section{Diálogo con Descartes}

Sin pretender dar cuenta del pensamiento de Descartes, algunas de sus ideas pueden relacionarse con un concepto de sujeto: postura, límite, objeto, tiempo, inconsistencia del Otro y responsabilidad.

\section{Sujeto y postura}

Cuando Descartes (2011) se dirige "A los señores decanos y doctores de la sagrada Facultad de Teología de París” (p. 155), ubica la postura como fundamento del saber, y no, por ejemplo, una acumulación previa: “[...] no parece en verdad posible que los infieles puedan ser persuadidos de religión alguna, y casi ni siquiera de alguna virtud Moral [...]” (p. 155). Lo más importante, más allá de lo que saben, es su postura (no calificamos aquí el juicio mismo: "infieles"), aquella por la cual podrían ser persuadidos. Descartes no se dirige a entidades epistémicas, sino a la postura que requiere:

- Abandonar la sensibilidad y los prejuicios: “[...] aconsejo que lean estas cosas sólo los que puedan y quieran meditar seriamente conmigo y se- 
parar la mente de los sentidos y de todos los prejuicios [...]" (Descartes, 2003, p. 3);

- Distanciarse del sentido común: “[...] los juicios de muchos son tan desmańados e inestables que se dejan influir más por las primeras opiniones recibidas, sin importar cuán falsas e irracionales sean, que por una refutación veraz y firme de éstas [...]” (Descartes, 2003, p. 3);

- Perder densidad psicológica en la operación;

- Aprender por razón natural (Descartes, 2011, p. 155) "que no es necesario buscar en otro lugar que en nosotros mismos, y que nuestro espíritu por sí mismo es capaz de suministrarnos" (p. 156);

- Complicidad: "no espero ningún aplauso del vulgo, ni gran número de lectores" (Descartes, 2003, p. 3); no intenta convencer a aquel que no quiere oír; al "infiel" no se lo puede disuadir, no porque no pueda pensar, sino porque no quiere;

- Aceptar que una argumentación hace depender unos enunciados de otros; quien no esté dispuesto a seguirla —y a hacerla por sí mismo-, no será tocado por los argumentos (Descartes, 2003, p. 3). Es el caso de quienes — "más arrogantes que doctos y juiciosos" (Descartes, 2011, p. 158) — proponen "valores" extraños a la argumentación;

- No fragmentar la línea argumentativa, pues quien parlotea ante cada cláusula, no lo hace sobre algo digno de refutación: “[...] muchos, queriendo adquirir la reputación de espíritus fuertes, no se preocupan sino de combatir con arrogancia las verdades más evidentes" (Descartes, 2011, p. 158);

- Entregarse a la búsqueda de la verdad, sin creer que "todas las proposiciones son problemáticas" (Descartes, 2011, pp. 157-158); no acepta que, antes de terminar una frase, alguien ya tenga una "opinión", una "crítica";

3 Tomando un par de citas del Seminario 20, sin considerar pertinente "la parte propiamente psicoanalítica de sus trabajos", Jean Bricmont y Alan Sokal dicen criticar a Lacan (1999, p. 35). 
- Dejarse convencer por argumentos que son capaces de convencer a otros (Descartes, 2003, p. 4), que pasan de unos a otros, que pueden transmitirse;

- $\quad$ Esperar: no se puede intervenir inmediatamente, a riesgo de no haber comprendido al autor (Nietzsche, 2009, p. 29).

Sin esta postura, sin "la esperanza de otra vida" (Descartes, 2011, p. 155) (¿un deseo?), preferimos lo útil a lo justo. Hoy diríamos que somos "pragmáticos", pues ahora llamamos "virtud" a la falta de implicación subjetiva. No han cambiado las cosas en tres siglos: "se proponen con frecuencia mayores recompensas por los vicios que por las virtudes" (p. 155).

¿Qué tiene que ver la postura con el sujeto? La trascendencia de Sigmund Freud no es una nueva descripción de la realidad psíquica. Si el saber se decide comparando palabra y cosa, su fundamento sería la "realidad" y el sujeto quedaría por fuera. Sin embargo, en Malestar en la cultura (Freud, 1929)", la realidad es una excrecencia del yo, algo expulsado durante la constitución del psiquismo, no algo preexistente. Más bien, Freud interpoló una postura: una clínica que apunta a la condición humana; no una terapéutica, sino una ética. Y si la postura crea el objeto de investigación (Saussure, 1987, p. 23), el psicoanálisis no describe de otra manera "la misma realidad"; la definición de la realidad en juego se resuelve después (Freud, 1915a), para que la duda no impida el acto. Esta postura clínica produce otra: al obtener la diferencia absoluta del analizante (Lacan, 1977, p. 279), se produce el sujeto, es decir, aquel que asume su modalidad de satisfacción y que no le atribuye su indigencia al otro, a la historia, al destino. Si no se vivencia el psicoanálisis, su teoría "no cala lo bastante hondo, y no crea convencimiento alguno" (Freud, 1925, p. 297).

En cambio, se descarta la postura cuando se toman entidades epistémicas, hechas de saber, o para el saber, como cuando hablamos de "Conocerse a sí mismo”. Para el psicoanálisis, no se trata principalmente de conocer, ni hay un "sí mismo". Por eso, no toma entidades epistémicas, sino sufrientes: el sufrimiento nos singulariza, mientras el saber nos disuelve en lo universal. Ahora

4 Para facilidad del lector se citan las obras de Freud en su fecha original de publicación. En las referencias se encuentra la información de las ediciones consultadas. 
bien, el psicoanálisis no cura del sufrimiento, pues este nos es constitutivo; más bien, hace emerger al sujeto (Lacan, 2008c, p. 571), el cual se hace cargo de su singularidad, deja de ostentar el sufrimiento o de culpar al Otro.

Una postura frente al saber permite asumir una axiomática, aceptar unas reglas del juego y producir enunciados de una disciplina ${ }^{5}$, en pos de satisfacerse con lo inteligible. Si se minimiza la postura, quedamos subsumidos en el "método", aflorando sólo como portadores del error. Podemos saber, pero a condición de quererlo y de trabajar en su consecución.

El saber, sin postura, conduce a lo peor.

\section{Sujeto y limite}

Primera objeción a las Meditaciones:

[...] del hecho de que la mente humana, al volverse sobre sí misma, no perciba ser más que una cosa pensante, no se deriva que su naturaleza o esencia excluya todas las otras cosas que acaso también pertenecen a la naturaleza del alma" (Descartes, 2003, p. 2).

El filósofo responde que, sin límites, no hay pensamiento posible. Encuentra que somos cosas pensantes, y el librepensador acepta, pero agrega: " $y$ también somos x, y, z...”. Es decir, soporta que el otro hable mientras llega su turno; no está a la altura de las reflexiones. Aceptada la cadena argumentativa, enunciados que no se desprendan de ella, son impertinentes. La argumentación no permite el desvarío; la conversación, sí. Los pasos de la demostración reducen poco a poco la libertad, hasta que, en el último, atados por los argumentos previos, estamos forzados a concluir de cierta manera. Si aceptamos jugar ajedrez, no podemos luego reivindicar la libertad de los peones y la abdicación del rey, en pos de un juego libertario.

Pero, ¿¿de dónde nos viene la falta de límite? De la lengua, pues los signos hablan de los signos (Eco, 1975), ad infinitum; "comprender una frase significa comprender un lenguaje" (Wittgenstein, 1998, p. 31). Dejada a sus propias

5 Cierta formación universitaria, en cambio, no produce la postura, sino que la supone ya dada y, entonces, pasa —en el mejor de los casos- a transmitir fórmulas con las cuales obtener enunciados "con iguales derechos", es decir: sin postura. 
reglas, la lengua no se detiene; no está programada para parar. Y los hablantes no garantizan que pare ${ }^{6}$. Se necesita que el sujeto decida parar. Cuando el hablante corta, se producen efectos de significación, pues sólo entonces se pueden evaluar — retroactivamente- los elementos de la frase, la modalidad de su uso, el registro, etc. ${ }^{7}$.

Cuando no hay corte, la persona es hablada por la lengua: disuelta en ella o arrasada por ella (un "loco", decimos). No hay sujeto cuando hablamos para describir el mundo, ambientar la co-presencia, o acusar al Otro de nuestra indigencia. Si el hombre es el estilo — dice el Conde de Buffon-, el estilo nos individuaría. Pero si el estilo es el hombre al que nos dirigimos (Lacan, 2008d, p. 21), "nuestro" estilo es del otro.

Los efectos significativos, debidos al corte, constituyen un sujeto postergado por la metonimia de la lengua. Así, el sujeto estaría en la manera de cortar: laguna, tartamudeo, frase inconclusa, interrupción, risa, llanto. Por eso, en la sesión analítica no hay confesión — como creen algunos—, no es parloteo que disuelve al sujeto. Ella divide al analizante, no lo busca en el sentido, sino en sus tropiezos. Por eso, termina con una puntuación. Mientras lo simbólico infinitiza (no pone límite), la puntuación analítica finitiza (Miller, 2012, pp. 156-157). El sujeto es asunto de límite.

También hay formas sociales de corte. El algoritmo, por ejemplo: antes, las estrellas hablaban sin parar de los hombres; la fórmula de la gravitación, las silenció (Lacan, 1984a, p. 249). Una teoría no es una lluvia de ideas, una apertura indefinida: tiene límite ${ }^{8}$.

La segunda objeción a Descartes dice que el lenguaje nombra lo existente, que carece de límite. El filósofo responde que el lenguaje crea lo inteligible, ámbito humano limitado lógicamente. Si lo humano se jugara en la deixis (señalar lo sensible), no se necesitaría la doble articulación de la lengua y bas-

6 Esta tendencia la podemos verificar en el recurso comercial de algunas compañías, cuyos anuncios apelan a la falta de límite: "Con DaviPlata sus recargas rinden más para que no pare de hablar".

7 Se tramita la frase "El perro de Juan...”, hasta que se cierre, o bien con “... tiene moquillo", o bien con “... se volvió a emborrachar”. Y, aún después de “tiene moquillo”, podría continuarse: “...'moquillo' es una marca de licor", etc.

8 La importancia del límite está en la observación de Descartes a la primera meditación (a propósito del juego), pero también está en Immanuel Kant (2003): el impulso es una falta de límites. Y también está en la idea de diques (asco, vergüenza y moral) que propone Freud (1905). 
taría con los códigos de señales de los animales (Benveniste, 1971), a quienes no llamamos sujetos (la vida animal no requiere objetos inteligibles).

\section{Sujeto y objeto}

Según la primera meditación, reconocer por mucho tiempo ciertas ideas como verdades, no implica que sean verdaderas. La costumbre y el reconocimiento no son fuente de certeza. El reconocimiento no proviene principalmente de la razón y, por tanto, no es demostrable — ni desmontable — desde la razón. Descartes percibe que ha montado su sistema de comprensión sobre bases dudosas. La certeza de una idea (sin importar cómo la obtuvimos) proviene de su nexo con el afecto (Freud, 1927, p. 31). Así, cuando le apuntamos como si se sostuviera en argumentos, erramos el tiro. Al proponerse demoler los cimientos, para dar una base firme a las ciencias, Descartes también va a la postura: allí arraigan tales cimientos, no en una axiomática o en las reglas del juego de una ciencia. De tal manera, se autoriza en sí mismo... ¡lo cual es un principio de la posición subjetiva en psicoanálisis! Por eso puede incluso poner en entredicho a Dios (hasta ese momento). Se pone al servicio de la axiomática geométrica mientras, cortésmente, destaca los atributos de los decanos y doctores de la sagrada Facultad de Teología de París.

Por su parte, el psicoanálisis saca certeza del síntoma: cuando una hipótesis sobre el caso en análisis le es comunicada al paciente, la certeza no viene de su aprobación ("el afectado" sabría si es acertada), ni de su desaprobación (dadas las "resistencias" del paciente). No es el caso de con cara gano yo, y con sello pierde usted: Freud (1937b, p. 259), recordando ese adagio, muestra que la certeza no proviene de los razonamientos de uno u otro, sino del síntoma: por ejemplo, un súbito agravamiento, una vez comunicada la construcción.

Descartes "libre de toda preocupación", y habiéndose procurado "un seguro reposo en una soledad apacible [...]" (2011, p. 165), habla de sus propios fundamentos, toma su decisión y, sin embargo, obtiene un principio universal. Igual Freud: saca conclusiones universales a partir de unos pocos casos. Ahora bien, la obtención de asertos con pretensión de universalidad, ¿siempre depende del "tamaño de la muestra"? Según Alain Desrosières (1995), la estadística 
dejó de hacer monografías sobre cada Estado — de ahí su nombre—, y pasó a comparar las cifras de diversos Estados, a partir de hacer equivalencias. Muchas cosas ocurrieron para que hoy nos parezca evidente que una parte puede representar el todo (Milner, 2004)... con un "margen de error". Sin embargo, no todos los objetos de investigación tienen la misma configuración. Freud concluyó sobre lo humano, entrevistando a unos pocos neuróticos, pues hay una homología entre el síntoma y las formaciones del inconsciente (sueños, lapsus, chistes, olvidos), presentes en todas las personas. Pues bien, Descartes está en una situación similar: socavando los principios de sus propias certezas, busca una base sólida para las ciencias; no necesita una muestra representativa, pues el pensamiento es característico de todos los humanos. Le basta consigo mismo. Su objeto no es estocástico.

También por eso, el psicoanálisis se ocupa del "caso por caso": pone sus categorías (universales) no para sostener el universal, sino al servicio de la singularidad (Miller, 2011, p. 98). No se queda en lo universal ni en lo singular.

Descartes (2011) destruye sus antiguas opiniones, para buscar "algo firme y constante en las ciencias" (p. 165). Y, para ese atravesamiento, se procura - a posteriori - una garantía. O sea, tiene como horizonte lo universal. Destruye unas creencias, en el sujeto, para dar algo firme a las ciencias... pero, luego, nada le restituye al sujeto. El saldo es para las ciencias; el sujeto queda despojado, sin creencias. Es decir: las creencias (sentido e historia), que se oponen a establecer "algo firme y constante en las ciencias" (p. 165), no definen al sujeto; el sujeto es lo que queda después de destruir las opiniones. Ante esto, ¿pedir la restitución del sujeto, como Edgar Morin (1994), o denunciar el antihumanismo de la ciencia? Lacan (1984b) más bien se pregunta: ¿qué sujeto para ese hallazgo de Descartes? Esto se relaciona con la petición de Bachelard (1981) de ubicar a Descartes en consonancia con el ensanchamiento del que fueron objeto la física y la geometría, por parte de la física cuántica y de las geometrías no-euclidianas, respectivamente. De hecho, para Lacan es el filósofo de La Ciencia (mayúscula) formal, el que percibe que la Ciencia galileana expulsa el sujeto, lo cual lo hace visible. Y, de ahí en más, hacerse cargo del sujeto expulsado. 


\section{Sujeto y tiempo}

Descartes (2011) declara:

Pero como me parecía que tal empresa era enorme, esperé hasta haber alcanzado una edad que fuese tan madura, que no pudiese esperar que hubiese otra en la que estuviera en condiciones para ejecutarla; lo cual me ha hecho diferirla tanto tiempo, que en adelante creeré cometer una falta si continuara empleando en deliberar, el tiempo que me queda para obrar (p. 165).

Dejó pasar el tiempo, con el fin de hallarse en la edad propicia para acometer la obra; no obstante, de cara a la acción, detecta un retraso. Según el psicoanálisis, no hay momento justo: o hay retraso, o hay apresuramiento. Así mismo, no pasamos de la insuficiencia corporal (dada nuestra prematuración) a la suficiencia (tras un desarrollo fisiológico o psicológico), sino a la anticipación, alienándonos en la imagen del otro (Lacan, 2008a, p. 102). El acto de concluir "se adelanta a su certidumbre, debido a la tensión temporal de que está cargado subjetivamente, y que, bajo la condición de esa anticipación misma, su certidumbre se verifica en una precipitación lógica” (Lacan, 1990, p. 203). La espera de Descartes evita la acción; habla de esperar un momento propicio que, sin embargo, cuando ya no hay marcha atrás ("una edad que fuese tan madura, que no pudiese esperar que hubiese otra"), se revela como algo que precipita la decisión. Siente que lo importante es la decisión, y que lo colectado hasta ese momento — saber, por ejemplo_ — en realidad es distinto al hecho de actuar. Tras la conclusión sabremos si hubo lapso para comprender o procrastinación.

Para reflexionar sobre el tiempo lógico, Lacan (1990) menciona un apólogo sobre tres presos condenados a muerte, de los cuales puede ser indultado aquel que acierte con la respuesta a un problema lógico. La muerte precipitará la decisión. ¿Tengo colgado un aro blanco o uno negro? El razonamiento individual no es suficiente; se necesita la reacción del semejante para mover a la acción: que el otro no amague pararse es lo que permite actuar, pero como son iguales ("sujetos indefinidos salvo por su reciprocidad" [Lacan, 1990, p. 200]), todos se paran al mismo tiempo, con lo cual cada uno disuade a los demás; entonces, dudan, aunque sólo para concluir que los otros han obrado de igual 
forma y que, por esa vía, no habrá fin: se pararán sólo para sentarse a continuación y así en lo sucesivo; de tal manera, si no hay anticipación, incluso a riesgo de equivocarse, no hay solución. Son sujetos cartesianos, es decir, que no tienen espesor psicológico. Pues bien, Descartes enjuicia la instancia temporal, con criterio de tiempo lógico, no en función de los contenidos de pensamiento en juego. Dice Lacan (1990):

[...] introduce la forma del otro en cuanto tal, es decir, como pura reciprocidad, puesto que el uno no se reconoce más que en el otro y no descubre el atributo que es suyo sino en la equivalencia del tiempo propio de los dos (p. 202).

Descartes busca la verdad y se aísla, pero "si bien en esta carrera tras la verdad no se está sino solo, si bien no se es todos cuando se toca lo verdadero, ninguno sin embargo lo toca sino por los otros" (Lacan, 1990, p. 206).

Es decir, una "individuación” requiere una reacción del otro (Lacan, 1990, p. 202). No obstante, tal individuación se objeta en el momento del acto: abandonar la comprensión para pasar a la conclusión es abandonar al semejante; en el acto hay una desconexión instantánea con el Otro (Miller, 2010). Esto lo realiza Descartes (2011) de la manera más literal, propiciándose una situación "libre de toda preocupación [...] en una soledad apacible" (p. 165). Así, detener la comprensión es condición de la acción; su prolongación, así sea enunciada como el acopio de mejores razones para actuar, en realidad no puede más que aplazar la acción. Descartes dice que no va a gastar tiempo en deliberaciones, en tanto lo que ahora le resta es obrar... ¡y llama Meditaciones a su documento!... Él es quien medita, aunque en su acto no se piensa (y donde se piensa, no actúa, no es).

Cuando Descartes subvierte sus ideas y opiniones, ¿dónde se ubica? ¿Son ellas discernibles de lo que él es? ¿Desde dónde mirar aquello que permite mirar? Tenemos, entonces, un sujeto dividido (un dividuo, nunca un in-dividuo), pues éste podría ubicarse "por fuera de sî" para socavar esa certeza de ese otro que es él, para socavarse. De ahí que el cogito sea una paradoja que, de suyo, habla de la inconsistencia de buscar el ser por el lado de lo simbólico: si se opone ser/pensar, ¿cómo concluir que de pensar soy? Y es a nombre de lo otro (la prisa para actuar, el dios caprichoso), en medio de un drama, que se exige 
concluir. La división entre deliberar y obrar nos autoriza a extraer un punto de basta de lo simbólico, como punto vital del sujeto que ve aparecer la culpa (“[...] creeré cometer una falta si continuara empleando en deliberar, el tiempo que me queda para obrar" [Descartes, 2011, p. 165]) si no se desagrega por un momento del Otro.

Finalmente, si se trata de sacar una conclusión, ¿para qué Descartes narra la situación espacio-temporal en la que va a meditar? Algo similar ocurre en el Banquete de Platón: el quid del amor no está en alguno (o algunos) de los discursos, sino en la escena de celos de Alcibíades (Lacan, 2003). También Nietzsche (2009), cuando reflexiona sobre la educación, introduce una escena dramática... En los tres casos, se crea un contexto para el acto.

\section{Sujeto y Otro inconsistente}

Para Descartes, las ideas se destruyen demostrando, una a una, que son falsas; o demostrando que sus cimientos son falsos. El primer camino es infinito, pues la máquina no deja de producir enunciados: la lengua es una finitud abierta (Lyons, 1983). En cambio, el segundo camino es finito, pues tumba todo enunciado - incluso los venideros- edificado sobre cimientos objetados. Así hace Freud: la clínica psicoanalítica sería infinita si se ocupara de todos los enunciados del analizante, sin apuntar a la gramática9 ${ }^{9}$ Lo mismo hace la lingüística: investiga la máquina que hace posibles los enunciados de una lengua, no los enunciados mismos (Hjelmslev, 1980). Otro tanto pasa con el sujeto: es producto de la estructura; el "contenido" que se le adosa viene después, de las formas sociales de su concreción, que requieren un sujeto interpelable por ese llamado. La producción estructural del sujeto es distinta a la subjetivación histórica. Como dependiente de una máquina que hace enunciados tocados por la pulsión, el sujeto no estaría reducido al sentido, y sería finito; como suma de sus enunciados, estaría densificado por el sentido, y sería infinito. Esta opción busca "recuperar el sentido", "dar sentido", incluso "dar la palabra”; llama a hacer autobiografías, encuestas, estudios de caso; tal

9 Número finito de elementos, que se relacionan entre sí a partir de unas reglas específicas, también finitas; este montaje da lugar a infinitas frases. 
procedimiento, aunque interrogue al Otro, termina inventándole consistencia. La primera opción no da sentido, busca la forma de la que el sentido es una elucubración; no busca el saber en la interioridad ni en el contexto. Se fundamenta en la inconsistencia del Otro y no intenta restituirla.

Ante un sujeto dividido (por la inconsistencia), Descartes busca un Otro de la certeza. Igualmente, una terapia cognitiva, que se topa con un sujeto dividido (por el síntoma), busca que el paciente no se aparte de la curva normal. Descartes: de pensar bien, soy; terapia cognitiva: de pensar bien, estoy bien. Sin embargo, el punto de partida (la inconsistencia, el malestar), no podrá deshacerse al final. La certeza no unifica al sujeto; le es externa, incompatible con su especificidad. La ciencia busca la certeza, a expensas del sujeto; no obtiene la consistencia del sujeto, ni aun tomándolo como objeto.

Entonces, hay que tratar la gramática ("los principios sobre los cuales se apoyaban todas mis viejas opiniones” [Descartes, 2011, p. 166]) y no los enunciados. Igual para Wittgenstein $(1973, \$ 4.003)$ : como muchas "preguntas" filosóficas son pseudo-problemas y, por lo tanto, irresolubles, la filosofía debe plantear bien las preguntas (hacer funcionar bien la gramática). ¡El mismo propósito de Descartes de buscar la certeza!; les urge hacer consistir al Otro. Con todo, poner coto al mal uso de la gramática, es un buen remedio, sí, pero para el Otro; poco tiene que ver con la inconsistencia del sujeto. Es, incluso, al contrario: a más consistencia del Otro, más angustia para el sujeto (Lacan, 2006).

A cada juego del lenguaje, una garantía para establecer si los enunciados son o no verdaderos, si está bien usada la gramática. O sea: verdad/falsedad para el plano de los enunciados; y Verdad para el plano de la garantía (del Otro):

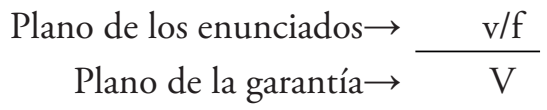

De ahí la sensación de que el Otro-garantía es omnisciente y que los otros (con minúscula) pueden decir verdad o falsedad; por eso, a Descartes la idea de un Dios engañoso (que él mismo introduce) le parece una herejía. Hoy par- 
timos de otro referente: lo "colectivo" (wiki, redes sociales, etc.). Hay algo estructural en juego: sólo un referente que trascienda a los semejantes impedirá que se destruyan (Hegel, 1997). Descartes busca El referente; y lo encuentra, tras un rodeo, en Dios. Como es una condición estructural del vínculo humano, y no meramente una creencia de momento, Lacan (1977, p. 69) dirá: Dios no ha muerto, es inconsciente. Por eso, no señalaremos la defectibilidad de tal referente, por el hecho de que la Modernidad lo encuentra en otro lugar. Continúa incólume su necesidad, aunque se cambie de referente. Y, cuando no lo hay, hay efectos calamitosos.

Para Descartes, Dios es una garantía; no es un semejante —otro, con minúscula- a quien podemos decir qué puede y qué debe hacer: "Los faltos de juicio atribuyen a Dios afectos humanos, con el fin de poder impugnarlo" (Descartes, 2003, p. 3). Eso es posible con el semejante (registro imaginario), no con la garantía buscada (registro simbólico).

El psicoanálisis coincide con Descartes en no tomar el camino infinito de los enunciados, pero no busca la garantía, pues se basa en la inconsistencia del Otro, en la imposibilidad de fundamentar con certeza. Lejos del discurso cínico, opera con la anomalía inherente a los sistemas lógicos. Por eso, su polo a tierra es lo pulsional (el registro real). La consistencia teórica que busca es un intento de estar a la altura de la postura; por eso, hace teoría de la práctica; su práctica no es la aplicación de una teoría. Más que un Dios que no engaña (garantía del Otro), su tema es la angustia que no engaña (Lacan, 2006) (del lado del sujeto).

En el ser-hablante, los significantes no se atan a los significados (como manda la gramática), sino a cargas pulsionales; desde la Interpretación de los sueños (1899), Freud siempre hizo notar el desnivel entre las palabras y los afectos concomitantes ${ }^{10}$. El inconsciente está formado por palabras movidas por la pulsión. El modelo de comunicación estándar (sin pulsión) borra al sujeto: un individuo que usa el lenguaje, que ejerce el propósito comunicativo, que se dirige al semejante, que dice cosas razonables.

10 Otro ejemplo: su reflexión sobre Leonardo da Vinci (Freud, 1910). 


\section{Sujeto y responsabilidad}

Reabsorber el acto en la lengua, como pretenden lingüistas y filósofos del lenguaje (Miller, 2010, p. 187), diluye la responsabilidad. Para Freud, en cambio, sujeto es sinónimo de responsabilidad: a Dora, por ejemplo, le dice que forma parte del entramado que denuncia (Freud, 1901). Responder es correlativo de responsabilidad (Miller, 2007, pp. 120-121); por eso, Lacan (2008b) habló del sujeto del derecho: el que responde por sus actos, el imputable ${ }^{11}$.

La enunciación no depende de la garantía del Otro, no está en la gramática de la lengua. El enunciado "Soy alcohólico" se ajusta a la lengua y es aceptable (en el sentido de Chomsky [1975]) para hispanohablantes. Sin embargo, ¿cuál es la relación del sujeto con ese enunciado? El analista, que no habla su "idioma”, le pregunta: “¿Qué quiere decir eso?”: busca desagregarlo del conjunto del Otro, que hable en singular. ¿Es eso retomar el camino de los enunciados, en detrimento de la máquina que los produce? No: el psicoanálisis busca cómo cada sujeto ata su goce a lo que ha atrapado de la gramática del Otro, o sea, lalengua $^{12}$. Por eso, no es una terapia cognitiva o del lenguaje. Remite los enunciados a una gramática particular. Para el psicoanalista, las frases de los pacientes no son ejemplos de uso de la lengua, sino realizaciones de lalengua. En la cotidianidad, escuchamos al otro como productor de sentido, lo que le supone consistencia al Otro: tan pronto alguien dice algo, soltamos una fórmula universal: "Eso es estrés; descansa”, "Tómate una aguapanela caliente con limón”, etc. En cambio, escuchar al sujeto desde la falta de garantía obliga a buscar su gramática, su manera de gozar con el significante.

La gramática del sujeto es un número finito de elementos, relacionados entre sí gracias a una economía libidinal específica que da lugar a los usos repetitivos de las cosas, del prójimo, del lenguaje delante de los otros. El sujeto (en cuanto significante) se fija a un objeto que no se define (como el significante) en oposición a otro; es una escena estática, no reenvía a otra cosa, como ocurre al hablar. El sujeto no quiere poner en tela de juicio esta

11 Descartes usa el ejemplo de los locos. Acertadamente, toma el delirio como parte de la naturaleza humana.

$12 \mathrm{Al}$ unir artículo y sustantivo en este concepto, Lacan no sigue la norma, a semejanza del sujeto. 
escena de satisfacción (fantasma la llama Lacan) que excluye la comunicación: un goce sin Otro, a espaldas de los valores morales, de los efectos de significación. O sea: podemos "mejorar" el uso de una gramática, pero no tocaremos el régimen de goce del sujeto. La garantía que busca Descartes, la buena filosofía de Wittgenstein, en últimas cuentan con —abogan por- una síntesis del individuo, algo imposible, dada la deflación de la imagen, el aplazamiento de las palabras que nos vindicarían, y la dificultad para defenderse de la pulsión (Miller, 2007, p. 126).

Para ir contra los propios principios (Descartes), se puede buscar apoyo en la garantía del Otro (la lógica, por ejemplo), o en la singularidad: una gramática hasta cierto punto excluida del Otro, producida en ausencia de la garantía que de él provendría. Este segundo caso se realiza mediante el acto, el cual reduce el excedente de elucubración: ahora el sujeto decide hasta dónde su goce va a pasar por las palabras, en dónde va a poner la puntuación; dejará caer algunos lastres y obtendrá un plus de satisfacción.

Si la gramática de la lengua funcionara "bien" en nosotros, si hubiera garantía, no habría fantasma, no habría síntoma, no habría lalengua. Tales autómatas no necesitarían el psicoanálisis. Ciertamente, cuando hacemos enunciados, pasamos por el Otro para tener un significado. Pero como el lenguaje no es de la misma estofa que el cuerpo, aparece la pulsión. Entonces, el Otro falla e inventamos el fantasma. En ese sentido, quedar atrapados del reenvío significante, algo a lo que presiona la interpretación del síntoma, es impedir el paso a lo que, justamente por no reenviar, no pertenece a, no está comprometido con, el estatuto de lo simbólico.

\section{Diálogo con Simondon}

Luego de una aproximación somera, sin olvidar que el trabajo de Simondon requiere una profunda dedicación (debido a su complejidad y desarrollo), que no he realizado, me animo a relacionar el concepto sujeto del psicoanálisis con un par de ideas sobre la individuación propuestas por el autor. 


\section{El objeto de investigación}

La introducción al texto La individuación... (2015), concreta la preocupación de Simondon: "la realidad que interesa, la realidad a explicar es el individuo en tanto individuo constituido" (p. 7); además, habla del "individuo con sus caracteres definitivos" (p. 8), de la individuación como el "momento crítico en el que aparecen la unidad y la coherencia" (p. 295), del "sujeto entero" (p. 306). O sea, da por hecha la individuación y procede a explicarla. En cambio, en relación con el sujeto, el psicoanálisis no se sorprende de que algo sea, de que tenga caracteres definitivos, unidad y coherencia, sino de que haya falta-de-ser ${ }^{13}$. Si de alguna consistencia da cuenta el psicoanálisis es de la del objeto de satisfacción, pero no del sujeto que se le adosa. El objeto es individuo (indivisible), el sujeto es dividuo (dividido).

Para el autor, la individuación es una "operación del ser completo" preindividual (Simondon, 2015, p. 10); sin embargo, tal ser completo no podría ser un antecedente del sujeto, pues éste surge de una estructura que porta una anomalía: el lenguaje es no-todo (Miller, 2009), lo cual tiene implicaciones en la producción del sujeto. En conclusión, la investigación del filósofo francés y la del psicoanálisis parecen definir objetos diferentes. De hecho, el texto de Simondon está dividido en dos partes: "Individuación física" e "Individuación de los seres vivos". Es decir, su individuo se realiza ya en lo físico y, luego, de manera más compleja, en lo vital: "El psiquismo y lo colectivo son constituidos por individuaciones que llegan luego de la individuación vital" (Simondon, 2015, p. 16). En cambio, si nos ocupamos de la lengua, no estudiamos los fenómenos físico ni orgánico que son, no obstante, soporte de la actividad verbal (de hecho, tales asuntos son explicados por otras disciplinas). El lenguaje no viene "luego" de la condición orgánica ${ }^{14}$ : es, más bien, una discontinuidad. De ahí que pase lo mismo con el sujeto en psicoanálisis: lo que

13 La expresión no es misteriosa: en una partida de ajedrez, por ejemplo, las piezas no tienen un "ser" definido; así, la dama podría pasar del máximo al mínimo valor, dependiendo de las posiciones relativas de las piezas; así mismo, un inversionista podría dejar de "ser" rico, de un momento a otro, por cuenta de la manera como se tasan las acciones en la bolsa.

14 Por eso, para Saussure (1987), el aparato vocal es secundario en el problema del lenguaje, pues "la lengua es una convención y la naturaleza del signo en que se conviene es indiferente" (p. 25). 
de él decimos presupone que está vivo, que tiene cerebro, pero no nos ocupamos de lo biótico ni de neuronal, pues el sujeto del que estamos hablando tiene otra especificidad, aunque requiera el soporte neurobiológico. El sujeto no viene "luego" del cuerpo (como la mariposa, de la crisálida): él también es una discontinuidad.

Néstor Braunstein (1980), médico y psiquiatra, hace al respecto un símil muy acertado: la cámara es soporte de la película, pero nadie intentaría explicar la película mediante la descripción de la cámara; para entender las películas, se requiere(n) otra(s) disciplina(s).

En relación con la división en partes de la obra en mención, es notorio que la "Individuación psíquica" esté subsumida en la segunda parte, es decir, en la "Individuación de los seres vivos". La diferencia que el hombre tiene con el resto de seres vivos no parece ser suficiente para darle otra especificidad. Toda la parte del libro relativa a la individuación de las unidades perceptivas (Simondon, 2015, p. 293), aplica más bien a los animales. Que la percepción sea una invención (p. 296), por ejemplo, está lejos de la creación humana, que permite producir lo que no existe (gracias al lenguaje), que sólo será perceptible después de haber sido pensado.

El sujeto está definido por el lenguaje, el cual echamos de menos en los animales, que tienen sus sistemas de comunicación (Benveniste, 1971). La información, según Simondon (2014), "le permite al sujeto situarse en el mundo" (p. 306); pero el humano no se adapta al mundo: porque está de espaldas al mundo y porque inventa "su mundo", aquel que responde al hecho del lenguaje. El humano es un ser vivo, sí, pero morti-ficado por la palabra; por eso, se diferencia de los otros seres vivos, al punto de ser objeto de investigación de nuevas disciplinas: historia, sociología, antropología. Así, no habría etología del ser-hablante y la primatología estudiaría su morfología, pero nada podrían decir del sujeto ${ }^{15}$. De igual manera, el psicoanálisis nada puede decir de un infarto cerebral en un humano (aunque sí de la manera como el sujeto lo asuma).

15 De hecho, se usan sus enunciados para agenciar una perspectiva no explicativa, sino política digamos-, que busca igualar al ser-hablante con los animales. A nombre de combatir la "arrogancia" del hombre con la naturaleza, se lo iguala. Y, entonces, no habría amor, sino química; no habría machismo, sino testosterona, etc. 
El psiquismo

Afirma Simondon (2015): "El psiquismo es persecución de la individuación vital en un ser que, para resolver su propia problemática [...]” (p. 16). Desde el concepto de sujeto que estamos usando, el psiquismo no persigue la individuación vital, pues, de un lado, el sujeto no tiene relación directa con la vida orgánica, toda vez que le dio la espalda cuando se desnaturalizó (Kant, 2003; Miller, 1998; Zuleta, 1986), o sea que no tiene instintos (que es parte del arsenal con que lo dota Simondon [2015, p. 306]). Y, de otro lado, es evidente que obra en contra de su propia vida, al punto que Freud acuńó el concepto de pulsión de muerte, que es una tendencia contrapuesta al principio vital que asiste a los seres vivos. Esto dibuja una tópica más compleja que la que permite definir la conciencia como "un régimen mixto de causalidad y de eficiencia, ligando, según este régimen, al individuo consigo mismo y con el mundo" (Simondon, 2014, p. 311), pues el ser hablante no es eficiente y de él podemos predicar algo más que un "sí mismo" perceptible por la consciencia. De hecho, Simondon (2014, p. 312) hablará de subconciencia, y dirá —equivocadamente- que el inconsciente del psicoanálisis es un "psiquismo completo" (p. 312), cuando se trata de una tópica de tres valores (inconsciente, preconsciente y consciente) (Freud, 1915b), en interacción constante.

Pero ¿por qué el psiquismo habría de perseguir la individuación vital? ¿Por qué ésta lo deja atrás (para que deba perseguirla)? Algo pasa con la vitalidad del ser al que le podemos atribuir un psiquismo. La desnaturalización (como efecto de asumir el lenguaje) explicaría mejor que la sencilla descripción simondoniana de lo que pasa. Es más: ese hiato entre el psiquismo y la individuación es una buena base para pensar al sujeto; no como aquél que "está obligado a intervenir él mismo como elemento del problema a través de su acción, como sujeto" (Simondon, 2015, p. 16).

Ante una escena masoquista (esto no tiene nada de rebuscado: es más cotidiano de lo que estamos dispuestos a reconocer), ¿vería Simondon la persecución de la individuación vital? Dice el autor que el ser del que podemos pregonar un psiquismo persigue la individuación vital "para resolver su propia problemática". Obsérvese que la "problemática" de este ser es autorreferencial: 
su propia problemática. No es el caso de los otros animales, a cuya "problemática” no la llamaríamos propia. ¿Por qué la contingencia vital del humano es distinta? ¿Por qué otros organismos viven problemáticas que no conforman un psiquismo? ¿Por qué aparece el psiquismo? El autor, a la zaga del asunto, atina a decir que este ser "está obligado a intervenir él mismo" ... pero, si no lo hiciera, habría que decir que "no está obligado a intervenir él mismo". Simondon describe lo que ve. Así mismo, la palma estaría obligada a emitir cocos; y, si no lo hace, pues no está obligada.

En lugar de esa supuesta obligatoriedad, es plausible plantear que el lenguaje, como estructura volcada sobre sí misma, marca todo lo humano: a diferencia de los códigos de señales que usan los animales (Benveniste, 1971), el lenguaje — que nos constituye — habla de sí mismo (la palabra palabra, por ejemplo); y, entonces, el trabajo, la ley, la sexualidad... todo se vuelve autorreferencial: el trabajo, además de productos, crea herramientas de trabajo; la ley humana no sólo regula, sino que también crea normas sobre las normas; la sexualidad humana se vuelca sobre sí misma y subordina la reproducción; etc. Comemos signos mediante la culinaria; nos protegemos del medio mediante la arquitectura. Bailamos, esculpimos, pintamos, hacemos música... Ésta sería la explicación que da lugar a que Simondon (2015) diga: "el sujeto puede ser concebido como la unidad del ser en tanto viviente individuado y en tanto ser que se representa su acción a través del mundo como elemento y dimensión del mundo" (p. 16). Y todo esto lo hace como sujeto. La individuación gana un nuevo estatuto: el sujeto (le agregaré el subíndice 0 , para diferenciarlo del sujeto del que venimos hablando). Pero ¿qué es eso? ¿Por qué el autor se ve en la necesidad de acuñar ese concepto?

Veamos: - el sujeto es un "viviente individuado"... pero todo viviente, ¿no está, forzosamente, individuado?; ¿ hay un viviente no individuado?; • "se representa su acción a través del mundo como elemento”... ¿por qué?, ¿por qué no puede estar en el mundo sin representárselo?, ¿̇o es algo que comparte con algunos animales?; • también se representa su acción como dimensión del mundo... ¿por qué el sujeto ${ }_{0}$, además de representarse el mundo como elemento también se representa como "dimensión del mundo"?; esta segunda representación, ¿está ausente en otros animales? 
Entonces, para el autor, el sujeto: persigue la individuación vital mediante el psiquismo; tiene una problemática propia; interviene como elemento del problema; se representa su acción como elemento del mundo y como dimensión del mundo. Pero estos elementos son una tautología, no constituyen una cadena causal de "soluciones" y respuestas; ya son la dimensión subjetiva: el psiquismo es el lenguaje hablando en nuestra cabeza, azuzado por la pulsión; la problemática es la condición subjetiva, cuando nos definimos por el lenguaje; la problemática es propia, porque el lenguaje es autorreferencial; la representación es elucubración imaginaria derivada del sistema significante ${ }^{16}$; y representarse como dimensión del mundo es el efecto de hablar: mientras los animales no saben que están vivos (no tienen un soporte para eso), el sujeto sí lo sabe (el lenguaje soporta esa certeza) y, por elucubración del sistema formal de la lengua, concluye que es algo más, una "dimensión del mundo"... pero, tarde o temprano, se preguntará por el sentido de eso y concluirá que está arrojado al mundo, que es parte del paisaje. Y es justamente esto lo que le revela su indigencia de ser.

Simondon hace una lista, no una secuencia.

\section{Lo transindividual}

Para introducir el colectivo en la definición de la individuación del ser psíquico, Simondon (2015) afirma que éste "no puede resolver su propia problemática en sí mismo" (p. 16). Dado que es evidente la participación del otro en la "resolución" de la propia problemática del ser psíquico (por eso vivimos en sociedad), se afirma que no puede en sí mismo. Y, si pudiera (volvemos a la palma), se diría que puede. No hay ahí explicación. ¿Por qué no puede? Pero, si tomáramos el lenguaje como ámbito de formación, el sujeto estaría repartido en dimensiones más complejas, una de la cuales sería lo colectivo: • atado a un significante que, a su vez, lo representa ante el Otro, $\bullet$ dividido por el intervalo significante $\mathrm{y} \cdot$ acicateado por el objeto pulsional (que cae como resto de la operación lingüística):

16 "Lo esencial del error es creer que la palabra tiene esencialmente como efecto comunicar, mientras que el efecto del significante es hacer surgir en el sujeto la dimensión del significado” (Lacan, 2006, p. 308). 


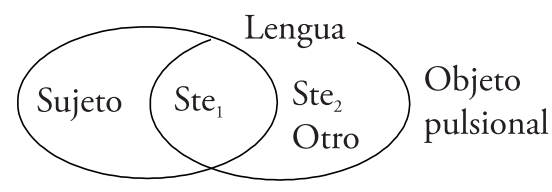

Así, el sujeto no es simplemente "un individuo de grupo". El grupo es una dimensión suya, justamente aquella en la que tiende a disolverse como sujeto. Freud dedica su texto Psicología de las masas y análisis del yo (1921) a mostrar que el ser hablante no es gregario, que las masas son reductibles a la psicología individual. Así, no habría una realidad preindividual que nos asocia al grupo, sino que una cadena de decisiones singulares — uno por unoda lugar al grupo (¡y a su peligro constante de disolución!). El sujeto no se constituye en unidad colectiva; más bien, se produce una identificación entre quienes ya han cedido su "instancia crítica" (Freud, 1921); ahora bien, a esa masa la podríamos llamar sujeto, en cierto sentido, pero el sujeto no queda constituido por el colectivo. Es más: el sujeto puede pertenecer, de forma simultánea, a diversos colectivos (incluso con referentes excluyentes). Ahora bien, Freud considera que esta manera de identificación es una renuncia a la responsabilidad (que otro piense y decida por mí). El sujeto no lleva en sí el colectivo; es una falta-de-ser, no lleva nada en sí (tal como el significante y como nos enseńó Descartes), aunque es capaz de hacer lazo, mientras despliega su modalidad autista de goce. Agrega Simondon (2015): "Las dos individuaciones, psíquica y colectiva, son recíprocas; permiten definir una categoría de lo transindividual que tiende a dar cuenta de la unidad sistemática entre la individuación interior (psíquica) y la individuación exterior (colectiva)" (p. 16).

La reciprocidad y la unidad sistemática entre las individuaciones interior (psíquica) y exterior (colectiva) es insostenible. La única posibilidad de reciprocidad sería entre significantes; pero ya vimos que el sujeto está parcialmente en el lenguaje, asido de una manera singular y acicateado por un resto. Mientras Simondon propone dos caras (interior y exterior), una por cada individuación, el sujeto que propone Lacan es una banda de Moebius, con una sola cara: recorriendo los asuntos colectivos, de pronto nos hallamos 
en el corazón del sujeto; y recorriendo su "intimidad", de pronto nos hallamos en medio de la sociedad.

Agrega Simondon (2014):

[...] su carga de realidad preindividual, al mismo tiempo que se individúa como ser psíquico que sobrepasa los límites del viviente individuado e incorpora lo viviente en un sistema entre el mundo y el sujeto, permite la participación bajo forma de condición de individuación de lo colectivo [...] (p. 16).

El autor pasa de decir que el ser psíquico no puede resolver en sí mismo su propia problemática (razón por la cual el colectivo interviene), a decir que el ser psíquico "permite la participación [...] de lo colectivo" (donde el colectivo llega con la venia del sujeto $)_{0}$. Pero, de un lado, la sujeción se da en medio de una imposición, pues la lengua no es natural (el autismo es un rechazo explícito a dicha imposición); y, de otro lado, requiere consentimiento, pero no como ejercicio de una "voluntad", sino como apuesta por un goce posible. Según la cita, la individuación como ser psíquico sobrepasa los límites del viviente (algo no visible, según decíamos, en la distribución de las partes del documento) y lo incorpora en un sistema entre el mundo y el sujeto . No obstante, desde la perspectiva aquí sostenida, el viviente quedó por fuera del mundo abierto por el lenguaje (en el que el sujeto tiene un pie); desde ese momento, el cuerpo estará marcado por el significante (véase, por ejemplo, el caso de la psicosomática), y vibrará en relación con el objeto pulsional (que requiere de lo simbólico, pues es su desecho).

\section{Conclusiones}

En relación con Descartes:

- Para Descartes, el saber está fundamentado en la postura, y Freud introdujo una postura: el acto clínico. Al buscar la diferencia absoluta, el psicoanálisis hace emerger al sujeto que responde;

- $\quad \mathrm{Si}$, ante la metonimia del significante, el hablante no decide puntuar, será hablado por la lengua; por eso, el psicoanálisis busca al sujeto en su modo de puntuar. El sujeto es asunto de límite; 
- Descartes y Freud concluyen a partir de pocos casos, dada la naturaleza de su objeto. El horizonte de Descartes es lo universal; el del psicoanálisis es lo singular. Tras despojar al sujeto, Descartes nada le restituye. Se deduce que es el efecto retroactivo de su exclusión;

- Más que lo colectado (saber), lo importante del acto es la decisión. Buscar "mejores razones para actuar", en realidad aplaza la acción. Estar entre deliberar y obrar sugiere un sujeto dividido;

- $\quad$ Descartes busca la verdad a través de la consistencia del Otro (Dios y la "comunidad virtual" realizan esa condición estructural), pero no le da consistencia al sujeto, que sólo después se subjetivará socialmente;

- El psicoanálisis interpela al sujeto para que responda por sus enunciados, por sus actos. Para ello, va a la gramática de lalengua, pues el sujeto está fijado al objeto pulsional. Así, no obrarán las operaciones que supongan la consistencia del Otro.

- En relación con Simondon:

- Simondon da por hecha la individuación, mientras que el sujeto es faltade-ser. La individuación, como "operación del ser completo" preindividual, riñe con la estructura no-toda (el lenguaje) de la que surge el sujeto. $\mathrm{El}$ individuo se realiza ya en lo físico y, luego en lo vital, mientras el sujeto es una discontinuidad en relación con lo físico y lo biológico. ¿Hay diferencia entre el hombre simondoniano y el resto de animales?; en todo caso, el sujeto está definido por el lenguaje, inexistente en los animales;

- $\quad$ El sujeto ${ }_{0}$ de Simondon persigue la individuación vital mediante el psiquismo; tiene una problemática propia; interviene como elemento del problema; y se representa su acción como elemento del mundo y como dimensión del mundo. Esta serie descriptiva se unifica en el sujeto como efecto del lenguaje: la lengua habla en nuestra cabeza, hace que lo humano sea autorreferencial y pide elucubraciones a partir de la estructura formal;

- Lo transindividual no resuelve colectivamente la problemática subjetiva, pues nuestros problemas ya son lingüísticos, no atañen a un ámbito nue- 
vo de producción del sujeto. El sujeto está atado a un significante que, a su vez, lo representa ante el Otro (grupo), pero también está dividido por el intervalo significante y acicateado por el objeto pulsional (resto de la operación lingüística). No hay una realidad preindividual que nos asocia al grupo, sino que una cadena de decisiones singulares da lugar al grupo. 


\section{REFERENCIAS}

Bachelard, G. (1981). El nuevo espiritu cientifico. México: Nueva Imagen.

Benveniste, É. (1971). Comunicación animal y lenguaje humano. En Autor. Problemas de lingüistica general I. México: Siglo xxi.

Borges, J. L. (1974). Funes el memorioso. En Artificios. En Obras Completas. Buenos Aires: Emecé.

Braunstein, N. (1980). Psiquiatría, teoría del sujeto, psicoanálisis (hacia Lacan). México: Siglo XXI.

Bricmont, J. \& Sokal, A. (1999). Las imposturas intelectuales. Barcelona: Paidós.

Chomsky, N. (1975). Aspectos de la teoría de la sintaxis. Madrid: Aguilar.

Descartes, R. (2003). Prefacio al lector. En Meditaciones metafísicas. Bogotá: Panamericana.

Descartes, R. (2011). Meditaciones metafísicas. Madrid: Gredos.

Desrosières, A. (1995). ¿Cómo fabricar cosas que se sostienen entre sí? Las ciencias sociales, la estadística y el Estado. Archipiélago, 20, 19-32.

Eco, U. (1975). La estructura ausente. Barcelona: Lumen.

Freud, S. (1899 [1990]). La interpretación de los sueños. En: Obras completas, Vols. IV y V. Buenos Aires: Amorrortu.

Freud, S. (1901 [1990]). «Fragmentos de análisis de un caso de histeria». En: Obras completas, Vol. VII. Buenos Aires: Amorrortu.

Freud, S. (1905 [1990]). «Tres ensayos de teoría sexual». En: Obras completas. Vol. VII. Buenos Aires: Amorrortu. 
Freud, S. (1910 [1990]). «Un recuerdo infantil de Leonardo da Vinci». En: Obras completas, Vol. XI. Buenos Aires: Amorrortu.

Freud, S. (1915a [1990]). «Pulsiones y destinos de pulsión». En: Obras completas. Vol. XIV. Buenos Aires: Amorrortu.

Freud, S. (1915b [1990]) «Lo inconsciente». En: Trabajos sobre metapsicología. En: Obras completas, Vol. XIV. Buenos Aires: Amorrortu.

Freud, S. (1919 [1990]). "Pegan a un niño". Contribución al conocimiento de la génesis de las perversiones sexuales». En: Obras completas, Vol. XVII. Buenos Aires: Amorrortu.

Freud, S. (1921 [1990]). Psicología de las masas y análisis del yo. En: Obras completas, Vol. XVIII. Buenos Aires: Amorrortu.

Freud, S. (1925 [1990]). «Prólogo» a August Aichhorn, Juventud descarriada. En: Obras completas, Vol. XIX. Buenos Aires: Amorrortu.

Freud, S. (1927 [1990]). El porvenir de una ilusión. En: Obras completas. Vol. XXI. Buenos Aires: Amorrortu

Freud, S. (1929 [1990]). Malestar en la cultura. En Obras completas, Vol. XXI. Buenos Aires: Amorrortu.

Freud, S. (1937a [1990]). «Análisis terminable e interminable». En: Obras completas. Vol. XXIII. Buenos Aires: Amorrortu.

Freud, S. (1937b [1990]). «Construcciones en el análisis». En: Obras completas. Vol. XXIII. Buenos Aires: Amorrortu.

Hegel, G. W. F. (1997). Fenomenología del espíritu. Bogotá: Fondo de Cultura Económica.

Hjelmslev, L. (1980). Prolegómenos a una teoría del lenguaje. Madrid: Gredos.

Kant, I. (2003). Pedagogía. Madrid: Akal.

Lacan, J. (1977). Los cuatro principios fundamentales del psicoanálisis (Seminario 11). Barcelona: Barral.

Lacan, J. (1981). Aun (Seminario 20). Barcelona: Paidós.

Lacan, J. (1984a). Las psicosis (Seminario 3). Barcelona: Paidós.

Lacan, J. (1984b). Subversión del sujeto y dialéctica del deseo en el inconsciente freudiano. En: Escritos II. México: Siglo XXI, 1984. 
Lacan, J. (1990). El tiempo lógico y el aserto de certidumbre anticipada: un nuevo sofisma. En Escritos I. México: Siglo XXI.

Lacan, J. (2003). La Transferencia (Seminario 8). Buenos Aires: Paidós.

Lacan, J. (2006). La angustia (Seminario 10). Buenos Aires: Paidós.

Lacan, J. (2008a). El estadio del espejo como formador de la función del yo tal como se nos revela en la experiencia psicoanalítica. En Escritos 1. Buenos Aires: Siglo XXI.

Lacan, J. (2008b). Introducción teórica a las funciones del psicoanálisis en criminología. En Escritos 1. Buenos Aires: Siglo XXI.

Lacan, J. (2008c). La dirección de la cura y los principios de su poder. En Escritos 2. Buenos Aires: Siglo XXI.

Lacan, J. (2008d). Obertura de esta recopilación. En Escritos 1. Buenos Aires: Siglo XXI.

Lacan, J. (2014). El deseo y su interpretación (Seminario 6). Buenos Aires: Paidós.

Lyons, J. (1983). Lenguaje, significado y contexto. Barcelona: Paidós.

Miller, J.-A. (1998). Freud y la teoría de la cultura. En Elucidación de Lacan. Buenos Aires: Paidós.

Miller, J.-A. (2001). El ruiseñor de Lacan. En Del Edipo a la sexuación. Buenos Aires: Paidós.

Miller, J.-A. (2007). Salud mental y orden público. En Introducción a la clínica lacaniana. Madrid: Gredos.

Miller, J.-A. (2009). La lógica del significante. En Conferencias porteñas (Tomo 1). Buenos Aires: Paidós.

Miller, J.-A. (2010). Jacques Lacan: observaciones sobre su concepto de pasaje al acto. En C. Bardón \& M. Puig (comps.), Suicidio, medicamentos y orden público. Madrid: Gredos.

Miller, J.-A. (2011). Sutilezas analíticas. Buenos Aires: Paidós.

Miller, J.-A. (2012). Monólogo de la apalabra. En La fuga del sentido. Buenos Aires: Paidós.

Milner, J.-C. (2004). Intervenciones en el Seminario de la Orientación Lacaniana de Jacques-Alain Miller. En Psicoanálisis y politica. Buenos Aires: EOL-Grama. 
Morin, E. (1994). La noción de sujeto. En Nuevos paradigmas, cultura y subjetividad. Buenos Aires: Paidós.

Nietzsche, F. (2009). Sobre el porvenir de nuestras escuelas. Barcelona: Tusquets.

Saussure, F. (1987). Curso de lingüistica general. Madrid: Alianza.

Simondon, G. (2015). La individuación a la luz de las nociones de forma y de información. Buenos Aires: Cactus.

Wittgenstein, L. (1973). Tractatus lógico-philosophicus. Madrid: Alianza.

Wittgenstein, L. (1998). Cuaderno azul. En Los cuadernos azul y marrón. Madrid: Tecnos.

Zuleta, E. (1986). El proceso de desnaturalización. Boletín de estudios psicoanalíticos, 1(1). 